\title{
Habilidades sociais: breve análise da teoria e da prática à luz da análise do comportamento
}

\author{
Alessandra Turini Bolsoni-Silva \\ Universidade Estadual Paulista, Bauru
}

\begin{abstract}
Resumo
O estudo do campo teórico-prático do THS é importante porque os seres humanos passam muito tempo engajados em interações sociais, e ao serem socialmente habilidosos, são capazes de promoverem interações sociais satisfatórias, as quais favorecem aumento de reforçadores e, portanto podem auxiliar na prevenção e/ou redução de dificuldades psicológicas. A prática da psicoterapia tem por objetivo garantir o bem-estar do cliente, não sendo diferente no caso da terapia comportamental que busca ajudar na descrição de funções de seus comportamentos, bem como no desenvolvimento de repertórios que lhe tragam reforçadores positivos e negativos. Parte destes repertórios a serem promovidos envolvem relacionamentos interpessoais, e o campo teórico-prático do Treinamento em Habilidades Sociais (THS) parece útil à Análise do Comportamento e à Terapia Comportamental, pois descreve comportamentos sociais passíveis de serem avaliados, sugerindo estratégias de intervenção efetivas. Diante destas considerações, este artigo pretende descrever e analisar alguns conceitos envolvidos no campo teórico-prático do Treinamento em Habilidades Sociais (THS), tecendo algumas considerações a partir da Análise do Comportamento.
\end{abstract}

Palavras-chave: habilidades sociais; análise do comportamento; terapia comportamental.

\section{Abstract \\ Social skills: brief analysis of the theory and praxis according to the behavioral analysis}

The fact that the theoretical-practicum study of the SST (Social Skills Training) is considered of main importance due to the fact that the human beings spend a great amount of time engaged in social interactions. Therefore, if they are socially skilled, they are able to promote satisfactory social interactions, which facilitate the increase of reinforcing situations and thus help to prevent and/or decrease psychological difficulties. In this view, the objective of the practice of psychotherapy, including the behavioral therapy, is to guarantee the client's well-being. The frame of work of the behavioral therapy is to provide a description of the client's behavior goals, as well as to develop a program that brings both positive and negative reinforcers. Part of this program involves interpersonal relationships, making the theoretical-practicum study of the SST to be of great value to the Behavior Analysis and to the Behavior Therapy. This is because it describes social behaviors that are possible to be evaluated, suggesting effective intervention strategies. In face of these considerations, this article attempts to describe and evaluate some concepts involved in the theoretical-practicum study of the SST, pin-pointing some considerations from the evaluation of the behavioral analysis.

Keywords: social skills; behavior analysis; behavioral therapy.

O estudo do campo teórico-prático do THS é importante, segundo Caballo (1997), porque os seres humanos passam a maior parte de seu tempo engajados em alguma forma de comunicação interpessoal e, ao serem socialmente habilidosos, são capazes de promoverem interações sociais satisfatórias. Esta forma de interagir favorece o aumento de reforçadores e portanto, pode auxiliar na prevenção e/ou redução de dificuldades psicológicas.

Conforme Del Prette e Del Prette (2001a), relacionamentos interpessoais sempre foram objeto de inte- resse e de investigação no estudo de várias abordagens psicológicas, tais como a psicanálise, a gestalt e o behaviorismo. Assim, relações sociais ${ }^{1}$ têm sido foco de estudo há bastante tempo, justificando o interesse na descrição destes fenômenos.

A prática da psicoterapia, conforme o Código de Ética da Psicologia (1999), tem por objetivo garantir o bem estar do cliente, não sendo diferente no caso da terapia comportamental que busca ajudar a pessoa a descrever as funções de seus comportamentos e desenvolver repertórios que lhe tragam reforçadores 
positivos e negativos. Parte destes repertórios, a serem promovidos, envolvem relacionamentos interpessoais, e o campo teórico-prático do Treinamento em Habilidades Sociais (THS) parece útil à Análise do Comportamento e à Terapia Comportamental, pois chama a atenção para comportamentos sociais passíveis de serem avaliados, sugerindo estratégias de intervenção efetivas, seja em atendimentos individuais, seja em grupos.

Diante destas considerações, este artigo pretende descrever e analisar alguns conceitos envolvidos no campo teórico-prático do Treinamento em Habilidades Sociais (THS), tecendo algumas considerações a partir da Análise do Comportamento.

O texto está organizado em dois tópicos: 1) habilidades sociais enquanto objeto de estudo, definindo termos como habilidades sociais, competência social e desempenho social, bem como modelos explicativos que o THS propõe para o estabelecimento e manutenção de interações sociais; 2) alternativas de trabalho com habilidades sociais, que pretende descrever, em linhas gerais, estrutura de THS, aplicações para intervenção e pesquisa.

\section{HABILIDADES SOCIAIS ENQUANTO OBJETO DE ESTUDO}

Neste tópico são apresentadas definições de habilidades sociais e de competência social, seguidas de descrições acerca de avaliação de desempenho social e de modelos explicativos.

\subsection{Habilidades sociais}

A origem do movimento das habilidades sociais (HS) é freqüentemente atribuída a Salter (1949), considerado um dos pais da terapia comportamental, o qual promoveu técnicas para aumentar a expressividade verbal e facial descritas em seu livro Conditioned Reflex Therapy. Em 1958, Wolpe utilizou pela primeira vez o termo "comportamento assertivo", referindose à expressão de sentimentos negativos e defesa dos próprios direitos (Caballo, 1996).

Não há consenso quanto à definição de habilidades sociais (HS), porém, o termo HS geralmente é usado para designar um conjunto de capacidades comportamentais aprendidas que envolvem interações sociais (Caballo, 1995; Del Prette \& Del Prette, 1999). Abaixo são apresentadas algumas definições para análise.

MacKay (1988) critica a definição sobre HS de Alberti e Emmons (1970), a qual enfocaria mais o comportamento da pessoa que o sucesso da interação, pois coloca que a pessoa assertiva é aquela que age em seu interesse, é responsável por si mesma sem sentir ansiedade inadequada, expressa seus sentimentos de forma honesta e exerce seus direitos sem negar os direitos dos outros. De fato, a pessoa, ao interagir, o faz conforme uma história prévia (antecedentes), e o seu comportamento tem um efeito no interlocutor (consequiências), o que fatalmente influenciará comportamentos futuros, podendo aumentá-los de freqüência ou suprimi-los, além disso, eventos privados ${ }^{2}$, enquanto sensações corporais verbalizadas como ansiedade, são subprodutos de contingências, no caso aversivas (Tourinho, 1999).

Alberti e Emmons (1978) parecem ter revisado a definição de 1970 atribuindo maior importância às consequiências obtidas diante de respostas sociais assertivas, não-assertivas e agressivas. Assim, assertividade seria o processo pelo qual o indivíduo (emissor) expressa sentimentos, pensamentos ao receptor de forma adequada, ou seja, utiliza entonação, latência e fluência de fala apropriadas, ouve o receptor para então responder, de forma a atingir seus objetivos sem prejudicar as relações futuras com o mesmo (Alberti \& Emmons, 1978; Caballo, 1987). Não-assertividade ocorre quando o emissor não expressa seus sentimentos, seus pensamentos ao receptor emitindo, muitas vezes, comportamentos contra a própria vontade, ou deixando de defender-se por medo de prejudicar sua relação futura com o receptor, e por isso muitas vezes o emissor é explorado e prejudicado, sem contudo atingir seus objetivos. A não-assertividade nega e inibe a expressão de sentimentos, levando a pessoa a sentir-se ferida, ansiosa e autodesvalorizada, e por conseqüência raramente atinge os objetivos desejados. Já a agressividade, às vezes, permite atingir os objetivos desejados, mas no processo magoa os demais, fazendo escolhas por eles, além de os desvalorizar como pessoas, possibilitando represálias futuras. Por outro lado, o comportamento assertivo permite a autoapreciação do emissor e uma expressão honesta de seus sentimentos, geralmente atingindo os objetivos desejados, não prejudicando a si mesmo, nem o receptor.

Caballo (1991) apresenta uma definição que explicita um maior número de habilidades, quando comparada à de Alberti e Emmons (1978), pois afirma que comportamento socialmente habilidoso ou mais adequado refere-se à expressão, pelo indivíduo, de atitudes, sentimentos, opiniões, desejos, respeitando a si próprio e aos outros, existindo, em geral, resolução dos problemas imediatos da situação e diminuição da probabilidade de problemas futuros. No entanto, deixa de enfatizar habilidades não-verbais, tais como entonação, latência e fluência de fala apropriadas.

Del Prette e Del Prette (1999) esclarecem que as HS incluem a assertividade (expressão apropriada de sentimentos negativos e defesa dos próprios direitos) e também habilidades de comunicação, de resolução de problemas interpessoais, de cooperação, de desempenhos interpessoais nas atividades profissionais, além 
de expressão de sentimentos negativos e defesa dos próprios direitos. Porém, apesar desta distinção, os termos são comumente utilizados como sinônimos (Del Prette \& Del Prette, 1999; Falcone, 1998; Caballo, 1996).

Para maior detalhamento, vale apontar que Alberti e Emmons (1978) definem comportamentos nãoassertivos e agressivos como situacionais ou gerais. A não-assertividade, segundo Albert e Emmons (1978), divide-se em não-asserção situacional e geral. A nãoasserção situacional ocorre quando as pessoas se comportam de forma não-assertiva apenas em algumas situações que produzem ansiedade. A nãoasserção geral inclui as pessoas em que os comportamentos são tipicamente não-assertivos, sentindo-se incapazes de afirmar seus direitos ou agir de acordo com seus próprios sentimentos na maior parte ou em quase todas as situações; conseqüentemente possuem baixa auto-estima e muita ansiedade frente às situações sociais. A pessoa não-assertiva situacional pode reconhecer seu problema e rapidamente iniciar, com sucesso, a asserção, percebendo na sua vida diária maneiras de ser assertivo consigo mesmo e com os outros, sem ser instruído para isso. Já a pessoa nãoassertiva geral necessita de um tratamento terapêutico especializado para conseguir desenvolver a assertividade necessária.

A agressão, segundo os autores, também pode ser geral ou situacional, sendo que o indivíduo geralmente agressivo o é em todas as situações, e o indivíduo agressivo situacional o é em apenas algumas situações. A pessoa geralmente agressiva aparenta ter muita autoconfiança, mas pode ter atrito com a maioria das pessoas de sua convivência, sendo extremamente sensível à crítica, sentindo-se rejeitada boa parte do tempo e ansiosa em quase todas as situações sociais. Já a pessoa situacionalmente agressiva pode reconhecer esta dificuldade e buscar voluntariamente assistência ou aceitar a sugestão de alguém de que deve mudar e aprender respostas mais adaptativas que a agressão.

Comportamentos agressivos geralmente são sentidos, pelo interlocutor, como punições, a qual, conforme Skinner (1993a/1953), ao contrário do reforço positivo, traz desvantagens tanto para o organismo punido como para a agência punidora, gerando emoções negativas e predisposições para fugir ou contracontrolar.

Sidman (1995) afirma que a natureza e também a cultura pautam-se, muito freqüentemente, por práticas coercitivas. Nesta direção, valendo-se de Skinner (1993a/1953), a psicoterapia, enquanto audiência não coercitiva, tem por objetivo reduzir aversivos criados por outras agências controladoras (por exemplo religião, governo) e, portanto, cabe ao terapeuta ensinar formas de contracontrole mais eficazes na redução de aversivos e na maximização de reforçadores. O comportamento socialmente adequado, descrito acima, parece cumprir bem este papel, o que não é igualmente sentido com a inassertividade e/ou agressividade.

É possível apontar taxonomias para o comportamento socialmente adequado, sendo útil em processos de avaliações e de intervenções terapêuticas.

Para Caballo (1991), comportamento socialmente habilidoso implicaria as seguintes capacidades: iniciação e manutenção de conversações; falar em grupo; expressar amor, afeto e agrado; defender os próprios direitos; solicitar favores; recusar pedidos; fazer e aceitar cumprimentos; expressar as próprias opiniões, mesmo os desacordos; expressar justificadamente quando se sentir molestado, enfadado, desagradado; saber desculpar-se ou admitir falta de conhecimento; pedir mudança no comportamento do outro e saber enfrentar as críticas recebidas. As situações onde estas respostas podem ocorrer são muitas e variadas, como, por exemplo, ambientes familiar, de trabalho, de consumo, de lazer, de transporte público, de formalidade etc.

Já Del Prette e Del Prette (2001b) apresentam uma taxonomia mais completa, quando comparada com as de Caballo (1991), a qual é organizada em categorias amplas e específicas: 1) habilidades sociais de comunicação: fazer e responder a perguntas; gratificar e elogiar; pedir e dar feedback nas relações sociais; iniciar, manter e encerrar conversação; Del Prette e Del Prette (1999) apontam também para a adequabilidade de componentes verbais de forma na comunicação: duração, latência e regulação da fala; 2) habilidades sociais de civilidade: dizer por favor; agradecer; apresentar-se; cumprimentar; despedir-se; 3) habilidades sociais assertivas de enfrentamento: manifestar opinião, concordar, discordar; fazer, aceitar e recusar pedidos; desculpar-se e admitir falhas; estabelecer relacionamento afetivo/sexual; encerrar relacionamento; expressar raiva e pedir mudança de comportamento; interagir com autoridades; lidar com críticas; 4) habilidades sociais empáticas: parafrasear, refletir sentimentos e expressar apoio; 5) habilidades sociais de trabalho: coordenar grupo; falar em público; resolver problemas, tomar decisões e mediar conflitos; habilidades sociais educativas; e 6) habilidades sociais de expressão de sentimento positivo: fazer amizade; expressar a solidariedade e cultivar o amor.

Os autores acima apontam a importância do automonitoramento, definido "...como uma habilidade metacognitiva e afetivo-comportamental pela qual a pessoa observa, descreve, interpreta e regula seus pensamentos, sentimentos e comportamentos em situações sociais.” (p. 62).

Esta definição permite uma relação com a literatura da Análise do Comportamento, a qual define auto- 
conhecimento como a descrição das contingências das quais o comportamento é função (Tourinho, 1995) e, portanto a pessoa teria consciência ou autoconhecimento quando soubesse realizar análises funcionais do seu próprio comportamento, o que ocorre frente a uma comunidade verbal. Nas palavras de Skinner (1992/ 1957):

O autoconhecimento é de origem social. Só quando o mundo privado de uma pessoa se torna importante para as demais é que ele se torna importante para ela própria (...). Mas o autoconhecimento tem um valor especial para o próprio indivíduo. Uma pessoa que se tornou consciente de si mesma por meio de perguntas que lhe foram feitas está em melhor condição de prever e controlar seu próprio comportamento. (p. 31)

O autoconhecimento pode ser insuficiente para o comportar-se em situações sociais, já que pode haver déficits de habilidades sociais que necessitem de intervenções, pois, conforme Skinner (1993a/1953), variáveis que controlam o comportamento podem não ser manipuladas pela pessoa, e portanto, só o autoconhecimento não superaria as dificuldades. No entanto, o autoconhecimento é necessário para que pessoa seja capaz de automonitorar-se, e então possa observar, descrever e avaliar qual comportamento é adequado para dada situação social, a fim de aumentar a probabilidade de conseguir reforçadores positivos e negativos. Nesta direção, a psicoterapia é uma contingência especialmente treinada para "trazer à consciência" uma parcela daquilo que é inconsciente, ou seja, possibilita a descrição, através de perguntas, do que a pessoa faz e do por que ela faz (Skinner, 1995/1989).

Além dos componentes verbais das habilidades sociais (os expostos nas taxonomias previamente apresentadas), há também, conforme Del Prette e Del Prette (1999), componentes não-verbais da comunicação: olhar e contato visual; sorriso; expressão facial; gestualidade; postura corporal; movimentos com a cabeça; contato físico e distância/proximidade. Parafraseando os autores, a comunicação não-verbal ocorre quando a pessoa utiliza recursos do próprio corpo, excluindo-se a vocalização ${ }^{3}$, podendo assumir diferentes funções: a) substituição da linguagem, quando, por exemplo, certo membro de um grupo dá uma piscadela rápida, a qual tem o significado "você está de acordo?"; b) regulação na comunicação, onde gestos são utilizados para sinalizar quem deve tomar a palavra, interrompêla ou iniciá-la; c) apoio à comunicação verbal, quando a mensagem verbal parece incapaz de expressar totalmente os sentimentos, por exemplo, em velórios onde um forte aperto de mão, abraços razoavelmente demorados e delicados, passos lentos e postura comedida parecem dizer mais do que palavras; d) complementação da linguagem, quando a mensagem verbal é complementada pela não-verbal, por exemplo, movimentos circulares do indicador indicando "você é meio amalucado"; e) contradição da linguagem, onde o não-verbal é utilizado na indicação de não levar em consideração a fala, tendo função de brincadeira ou de ironia, por exemplo quando se diz "o salário está ótimo", ao mesmo tempo que se faz um gesto para baixo com o polegar.

Del Prette e Del Prette (1999), apesar de apontarem a adequabilidade do comportamento assertivo, chamam a atenção para algumas situação onde a assertividade não deveria ser exercitada, as palavras dos autores:

\begin{abstract}
...Em nossa experiência, idenficamos pelo menos três classes de situações em que a assertividade pode ter consequiências desfavoráveis ao emissor, ao receptor ou a ambos os pólos da interação: a) o caso de dificuldade do interlocutor em desempenho de tarefas profissionais (por exemplo, queixar-se de alguém que está se iniciando num emprego); b) na relação com pessoas extremamente suscetíveis ou portadoras de transtornos psicológicos, que podem se "descompensar" mais ainda; c) situações em que a assertividade contrasta notavelmente com os valores subjacentes à prática social (por exemplo, reagir a um chefe destemperado ou a uma autoridade militar que podem entender a assertividade como desacato ou quebra de disciplina) (p. 44).
\end{abstract}

Nestes casos, a pessoa pode comportar-se com inassertividade e procurar outras formas de contracontrole, como, por exemplo, procurando novo emprego, aproximando-se de pessoas reforçadoras e evitando o convívio com pessoas que trazem conseqüências aversivas.

Estando definido o termo habilidades sociais, cabe então definir competência social.

\subsection{Competência social}

Para avaliar certo repertório social, torna-se necessário definir competência social. Para Del Prette e Del Prette (1999) os conceitos de Habilidades Sociais e de Competência Social (CS) são freqüentemente empregados como sinônimos, no entanto, possuem definições distintas. O termo CS é utilizado em um sentido avaliativo, visando qualificar o nível de proficiência com que os comportamentos são ou deveriam ser emitidos, bem como sua congruência e adequação às 
dimensões pessoal e situacional (McFall, 1982; Del Prette \& Del Prette, 1996).

Nas palavras de Del Prette e Del Prette (2001b):

...defendemos a idéia de que as pessoas socialmente competentes são as que contribuem na maximização de ganhos e na minimização de perdas para si e para aquelas com quem interagem (...) o desempenho socialmente competente é aquele que expressa uma leitura adequada do ambiente social, que decodifica corretamente os desempenhos esperados, valorizados e efetivos para o indivíduo em sua relação com os demais" (p. 33).

McFall (1982) considera CS como uma avaliação geral refletindo um julgamento, com base em certo critério, acerca da adequabilidade do desempenho de uma pessoa diante de alguma tarefa. O autor coloca que o componente mais importante do termo CS é o conceito de tarefa, visto como um programa comportamental. Programa comportamental implica uma seqüência identificável de padrão de comportamentos provável de ocorrer. Isto significa que para compreender e predizer o comportamento de uma pessoa é necessário conhecer qual a tarefa está sendo realizada, bem como as regras sociais que a governam. Em síntese, o indivíduo socialmente competente possui HS específicas, referentes aos seus componentes cognitivo, motor e psicológico, favorecendo-lhe a obtenção de um desempenho adequado frente a determinada tarefa (McFall, 1982).

Desta forma, indivíduos socialmente competentes são, em geral, aqueles com tendência a apresentar seus sentimentos utilizando melhor a expressão corporal, com variação na postura e gestos e maior frequiência de perguntas. O oposto ocorre com os de menor competência social. (Del Prette \& Del Prette, 1996).

\subsection{Desempenho social}

O desempenho social, para Del Prette e Del Prette (1999, 1996), implica as dimensões pessoal, situacional e cultural.

A dimensão pessoal pode ser examinada em suas classes molares e moleculares de comportamentos. As classes molares são aquelas funcionalmente descritas, ou seja, "que se distinguem entre si em termos de seu efeito provável ou provavelmente pretendido no comportamento do outro" (Del Prette, 1985, p. 48), servindo na avaliação de necessidades e na definição de objetivos aos programas de desenvolvimento de HS. Elas podem ser organizadas (Del Prette \& Del Prette, 1996) em pelo menos dois conjuntos, de acordo com a natureza e origem das conseqüências prováveis ou pretendidas por um dos pólos interativos (ator e interlocutor): o de emissão (originadas no próprio autor) e o de reação (originadas no interlocutor), podendo ser positiva e negativa (quando o emissor responde a um comportamento prévio do interlocutor expressando aceitação/aprovação ou rejeição/desaprovação de tal comportamento). Del Prette e Del Prette (1996) agrupam as classes moleculares em componentes nãoverbais (como contato visual ${ }^{4}$, postura), paralinguísticos (características da fala, como volume e entonação), verbais (características do conteúdo da fala, como incidência de perguntas, uso do eu e prolixidade), mistos (como afetividade e atenção) e características autonômicas e fisiológicas (por exemplo, resposta galvânica da pele e alterações respiratórias). Os indivíduos socialmente competentes geralmente apresentam melhor expressão verbal e não verbal, como variações de postura, maior tempo de fala e maior frequiência de perguntas (Del Prette, Del Prette, Torres \& Pontes, 1998).

A dimensão pessoal inclui também os processos encobertos como expectativas, crenças e cognições (comportamentos privados), que acompanham os desempenhos interpessoais e que podem interferir de forma positiva ou negativa sobre esses desempenhos. Por último, a dimensão situacional caracteriza as demandas imediatas, os diferentes interlocutores (relação diádica ou grupal) e o contexto cultural mais amplo.

A dimensão situacional do comportamento sugere que as pessoas podem se comportar de forma socialmente adequada em um contexto e não em outro; por exemplo, elas podem ser habilidosas em ambientes de trabalho com colegas, autoridades e, no entanto, não generalizarem estas habilidades para o contexto de educação de filhos. Frente a isto, pode-se perguntar: por que esta generalização não ocorre? Uma explicação possível, à luz da análise do comportamento, seria que, como as pessoas são sensíveis às conseqüências de seus próprios comportamentos, neste caso, é possível que o comportamento socialmente adequado é mantido no ambiente de trabalho por ser reforçado, o que pode não estar acontecendo no ambiente familiar.

Desta forma, é preciso, para uma avaliação da competência social, considerar cada ambiente social como passível de análise funcional. Torós (1997) aponta para a necessidade de analisar funcionalmente a queixa apresentada (relações estímulo discriminativo - resposta - conseqüência), bem como analisar mútuas interdependências comportamentais do caso (relações resposta - resposta, além de relações entre estímulos, quando um altera a função do outro). Sturmey (1996) cita Goldiamond (1974) para dizer que o terapeuta precisa entender o propósito do comportamento para a pessoa, o que necessariamente implica análises funcionais mais amplas que tentem relacionar 
funcionalmente todo o repertório do cliente. Este raciocínio é interessante na avaliação do repertório social do cliente, considerando sua história prévia e atual de aprendizagem.

Finalmente, a dimensão cultural refere-se às semelhanças e diferenças entre culturas e entre momentos históricos que interferem no repertório social dos indivíduos.

Segundo Del Prette e Del Prette (1996), as três dimensões mencionadas devem ser consideradas simultaneamente, pois a caracterização das HS inclui os comportamentos encobertos, abertos, culturais e históricos das relações interpessoais. Na caracterização das HS é necessário também considerar fatores relacionados ao contexto histórico-cultural, indicando a importância de estudos na identificação dos padrões transculturais e na análise da influência de variáveis como sexo, idade, nível socioeconômico e habilidade comportamental das pessoas. Estes conceitos apresentados pelo campo teórico-prático do THS parecem congruentes com pressupostos da análise do comportamento, que descrevem qualquer comportamento como produto de três níveis de seleção, o filogenético (história da espécie), o ontogenético (história particular do indivíduo) e o cultural (história das práticas culturais (Skinner, 1984).

\subsection{Modelos explicativos}

Para um melhor entendimento do campo teóricoprático do THS, Del Prette e Del Prette (1999 e 2000) e Hidalgo e Abarca (1992) destacam cinco modelos que permitiram sua estruturação: o cognitivo, o da teoria de papéis, o da assertividade, o da aprendizagem social e o da percepção social.

O modelo cognitivo parte do pressuposto de que o desempenho interpessoal está relacionado com o processamento dos estímulos ambientais, dos fenômenos do ambiente social, em que o indivíduo organiza cognições e comportamentos frente a objetivos sociais ou interpessoais culturalmente aceitos, sendo que essas cognições causam comportamentos. Já o modelo da teoria dos papéis é derivado da Psicologia Social e está interessado no desenvolvimento da compreensão dos papéis sociais do indivíduo e das outras pessoas, bem como dos elementos simbólicos, verbais ou não, a eles associados, ou seja, analisa a flexibilidade do indivíduo em assumir diferentes papéis sociais. O modelo da assertividade apresenta duas vertentes; a primeira elaborada por Wolpe (1976) e Lazarus (1977) é referente ao paradigma do condicionamento respondente, onde a dificuldade no desempenho social dos indivíduos é vista como resultante da ansiedade interpessoal, buscando a sua superação através de técnicas de descondicionamento; por outro lado, a outra vertente situa-se no paradigma operante, em que a inabilidade social seria uma conseqüência da deficiência de controle de estímulos no encadeamento de respostas sociais ou a problemas específicos na aprendizagem de interações sociais, sendo enfatizado o reforço na aquisição, manutenção e fortalecimento dessas respostas. O modelo da aprendizagem social afirma que as habilidades sociais são aprendidas através de experiências interpessoais vicariantes, em que a observação do desempenho do outro (modelo) é vista como básica no surgimento do repertório social; o reforço é mais considerado como fator de desempenho de comportamentos já aprendidos do que de aprendizagem. Finalmente, o modelo da percepção social focaliza a habilidade de leitura (perceber e decodificar) do ambiente social, a qual é um dos aspectos do processamento cognitivo, permitindo ao indivíduo discriminar formas adequadas de se comportar frente aos diferentes padrões sociais.

Del Prette e Del Prette (1996) afirmam que os modelos acima mencionados não são totalmente excludentes, sendo possível verificar a predominância das tendências behaviorista e sociocognitivista. Conseqüentemente, os ensinamentos de cada um dos modelos são incorporados nos THS.

As conclusões de Del Prette e Del Prette (1996), acima mencionadas, são pertinentes, pois cada modelo parece recortar unidades de análises funcionais ${ }^{5}$, e portanto, podem ser utilizados no entendimento de interações sociais, por exemplo: a) é possível ler o modelo cognitivo e o de percepção social enquanto teorias que chamam a atenção para a importância de eventos privados, que na linguagem da análise do comportamento, seriam considerados enquanto estímulos discriminativos e/ou conseqüentes de dada contingência; b) a teoria dos papéis, ao apontar para flexibilidade em assumir diferentes papéis sociais, aponta para variabilidade do repertório social adquirida no decorrer de contingências de reforçamento (história ontogenética); c) os modelos da assertividade, tanto respondente como operante, também podem ser vistos enquanto recortes funcionais, pois respondentes incondicionados surgem diante de certos estímulos selecionados pela história da espécie e os respondentes condicionados são pareados diante da história ontogenética (operante); e d) Catania (1999/1998) concorda com a existência de aprendizagem por observação, afirmando que deve haver um componente filogenético; no entanto, alerta que

...a aprendizagem por observação deve incluir discriminações sutis das ações de um outro organismo e de seus efeitos de ações relacionadas por parte do observador... [portanto] devemos determinar seus componentes, em vez de usá-la 
para explicar outros tipos mais complexos de comportamento. (p. 239).

O próximo tópico apresenta alternativas de trabalho com habilidades sociais, bem como estrutura e técnicas comumente usadas.

\section{ALTERNATIVAS DE TRABALHO COM HABILIDADES SOCIAIS}

O THS busca superar déficits no desempenho social e promover interações sociais mais satisfatórias, através de procedimentos clínicos e educativos. Queixas individuais do cliente e sua adaptação devem ser compreendidas no contexto social imediato, percebendo o indivíduo como agente ativo na busca de relações sociais e interpessoais mais adequadas.

Segundo Del Prette e Del Prette (1996), a partir da década de 80 , programas de THS passaram a se destinar mais freqüentemente a uma clientela não clínica na busca de padrões mais satisfatórios de vida comunitária, como família, pré-escola, escola, pré-adolescentes e adolescentes. Esses programas (ver Del Prette \& Del Prette, 1997) vêm se direcionando de settings individuais para intervenções em grupo, onde o trabalho se mostrou mais efetivo, já que os conhecimentos de dado membro podem ser compartilhados com os demais, favorecendo trocas de experiências, opiniões, sentimentos etc.

Com relação à população não-clínica o THS pode assumir caráter educativo e preventivo (Del Prette, 1982), sendo viável, por exemplo, a pais que apresentam, ou não, queixas de comportamentos dos filhos e que queiram maximizar a qualidade de suas interações com os mesmos, como aconteceu no estudo de Silva, Del Prette e Del Prette (2000).

Del Prette e Del Prette (1996) afirmam que os programas de THS têm sido realizados em dois formatos: individual e grupo. Para Caballo (1996) o procedimento básico consiste em: a) identificar dificuldades quanto à inadequação social, ou seja, quais as queixas e problemas; b) realizar análise funcional a fim de identificar quais déficits impedem o comportar-se de forma socialmente adequada; c) informar o cliente sobre a terapia; d) iniciar o treinamento de habilidades deficitárias.

Del Prette e Del Prette (1999) afirmam que a estrutura de programas individuais e grupais, segue as seguintes etapas: a) informação sobre o método de tratamento; b) comunicação sobre as dificuldades interpessoais avaliadas; c) informação sobre a grande incidência de tais dificuldades, como forma de aliviar apreensões; d) exposição sobre o planejamento geral do programa; e) implementação do programa.
Os autores acima tecem algumas consideração quanto ao formato grupal. A partir de uma metaanálise da literatura, Del Prette e Del Prette (1999) apontam para uma tendência de escolha de grupos homogêneos, sem desconsiderar dificuldades individuais dos membros; o tamanho do grupo pode variar, no entanto, há uma preferência para um número que varie de oito a doze pessoas; cada sessão tem objetivos específicos e possui três partes, sendo a primeira de sondagem sobre interesses, problemas, tarefas de casa; a segunda refere-se à proposta de algum treinamento; e a terceira diz respeito à avaliação da sessão e atribuição de tarefas para casa.

Há vantagens na escolha de intervenções individual e grupal.

Algumas vantagens do treinamento individual segundo Bulkeley e Cramer (1994) (Em Del Prette \& Del Prette, 1999) são: avaliação contínua do desempenho na sessão, possibilidade de ensaios extensos e repetição dos mesmos, maior disponibilidade do terapeuta para modelar habilidades sociais específicas e modificação imediata de procedimentos que não estejam sendo efetivos.

O THS pode ser utilizado como parte de um processo terapêutico ou como o próprio processo. No caso de ser utilizado como parte de um programa individual mais amplo, em que o cliente possui diversas dificuldades, além das interpessoais, o atendimento individual pode ser um facilitador na discriminação de diferentes classes comportamentais problemáticas, bem como das interdependências funcionais entre elas.

Hidalgo e Abarca (1992) e Falcone (1998) afirmam que o treinamento quando estabelecido em grupo apresenta algumas vantagens:

- Favorece um ambiente social mais complexo e uma maior variedade de modelos, pois ocorre na presença de homens e mulheres com formas de vida distintas e experiências diversas.

- A experiência em grupo permite a aquisição de certas habilidades pois fornece oportunidades ao vivo.

- A atividade em grupo proporciona um meio protegido, o qual atua como intermediário entre a aprendizagem de certa habilidade e sua execução na prática real.

- Permite a reprodução similar de muitos encontros interpessoais favorendo a consolidação e generalização das condutas treinadas em situação de grupo.

- Proporciona feedback imediato à conduta treinada, tanto dos facilitadores quanto do grupo.

- Oferece possibilidades de soluções às questões propostas, e assim o indivíduo pode decidir entre diferentes tipos de respostas sem ter que recorrer 
unicamente à que propõe o terapeuta, ou seja, maior número de modelos comportamentais.

- Maior número de situações-problema e mais suporte para as suas soluções.

- O consenso do grupo sobre a eficácia de certa habilidade pode ajudar o terapeuta frente aos membros resistentes e/ou desqualificadores do tratamento.

- A atividade em grupo permite que a intencionalidade do vínculo com o terapeuta fique minimizada

- O treinamento em grupo permite a maximização dos recursos humanos e materiais.

No Treinamento em Habilidades Sociais são utilizadas técnicas de vários modelos conceituais, em especial da Análise Experimental do Comportamento ou da Terapia Comportamental (tais como ensaio comportamental, reforçamento, modelagem, modelação, feedback, relaxamento, tarefas de casa, dessensibilização sistemática) e de diversas abordagens cognitivas (por exemplo, terapia racional-emotivo-comportamental, resolução de problemas, parada de pensamento, modelação encoberta e instruções) (Del Prette \& Del Prette, 1999; Caballo, 1996).

Conforme Del Prette e Del Prette (1999), o THS pode ser utilizado na clínica (transtornos afetivos e de ansiedade; esquizofrenia; timidez e isolamento social; problemas conjugais e familiares; transtornos de personalidade anti-social) e na educação (ensino especial e regular). Enfim, qualquer demanda, seja familiar, escolar, de trabalho etc., em que pessoas possuam déficits de relacionamento interpessoal, pode ser beneficiada com um treinamento em habilidades sociais.

Além da utilização em intervenções individuais e grupais, o campo teórico-prático do THS tem sido útil na realização de pesquisas: a) de levantamento, por exemplo, nos estudos de Bolsoni-Silva (2002) e Silva (2000), que procuraram avaliar relações entre habilidades sociais de pais e repertório adequado e "inadequado" de filhos; b) de intervenção (por exemplo, Silva, Del Prette \& Del Prette, 2000; Del Prette, Del Prette \& Barreto, 1999; Del Prette, Z. A. P., Del Prette, A., Torres, A. C. \& Pontes, A. C., 1998; Del Prette, Z. A. P., Del Prette, A., Garcia, F. A., Silva, A. T. B. \& Puntel, L. P., 1998; Del Prette, 1985 e Del Prette, 1982), que avaliaram efetividade de procedimentos de intervenção, em diferentes populações. Estas pesquisas têm levantado questões de pesquisa pertinentes à educação, clínica e organizações, além de apontarem caminhos para futuros estudos na área ${ }^{6}$.

\section{CONSIDERAÇÕES FINAIS}

Este texto teve por objetivo discutir alguns conceitos do campo teórico-prático do treinamento em habilidades sociais (THS), tecendo considerações à luz da Análise do Comportamento, de forma a apontar algumas semelhanças e diferenças entre estes dois campos de conhecimento.

De forma geral, conclui-se que o THS é bastante útil para a Análise do Comportamento e para a Terapia Comportamental, tanto no atendimento a populações clínicas, como às não clínicas, visando à superação e/ou redução de déficits interpessoais, pois cumpre, pelo menos, dois papéis: a) descreve repertórios comportamentais sociais, bem como possíveis funções para dificuldades específicas, contribuindo para o processo de avaliação diagnóstica de casos clínicos; b) apresenta diversos procedimentos de intervenção para objetivos específicos, especialmente para atendimentos em grupos no estabelecimento de tais habilidades ${ }^{7}$.

\section{REFERÊNCIAS}

Abib, J. A. D. (1997). Teorias do comportamento e subjetividade na psicologia. São Carlos: Edufscar.

Alberti, R. E. \& Emmons, M. L. (1978). Comportamento assertivo: Um guia de auto-expressão. Belo Horizonte: Interlivros.

Andery, M. A. P. A.; Micheletto, N. \& Sério, T. M. A. P. (2001). Análise funcional na análise do comportamento. Em. H. J. Guilhardi; M. B. B. P. Madi; P. P. Queiroz \& M. C. Scoz (Orgs.), Sobre comportamento e cognição. Expondo a variabilidade (p. 148-157). Santo André: Arbytes Editora.

Bolsoni-Silva, A. T. (2002). O que os pais falam sobre suas habilidades sociais e de seus filhos? Argumento (7), ano 4, 71-86.

Caballo, V. E. (1987). Teoría, evaluación e entrenamiento de las habilidades sociales. Valência: Promolivros.

Caballo, V. E. (1991). El entrenamiento en habilidades sociales. Em V. E. Caballo (Org.), Terapía y modificación de conducta (p. 403-443). Madri: Siglo Veintiuno.

Caballo, V. E. (1995). Una aportación española a los aspectos moleculares, a la evaluación y al entrenamiento de las habilidades sociales. Revista Mexicana de Psicologia, 12(2), 121-131.

Caballo, V. E. (1996). O treinamento em habilidades sociais. Em V. E. Caballo (Org.), Manual de técnicas de terapia $e$ modificação do comportamento (p. 361-398). São Paulo: Santos Livraria Editora.

Caballo, V. E. (1997). El papel de las habilidades sociales en el desarrollo de las relaciones interpersonales. Em D. R. Zamignani (Org.), Sobre comportamento e cognição (p. 229-233). São Paulo: ARBytes Editora, $3^{\circ}$ Vol.

Catania, A. C. (1999). Aprendizagem: Comportamento, linguagem e cognição (4 $4^{\mathrm{a}}$ ed.). Porto Alegre: Artmed: Editora, (originalmente publicado em 1998).

Davis, F. (1979). A comunicação não-verbal. São Paulo: Summus.

Del Prette, A. (1982). Treinamento comportamental em grupo junto à população não-clínica de baixa renda: uma análise descritiva de procedimento. Dissertação de Mestrado. Pontifícia Universidade Católica de Campinas.

Del Prette, A. (1985). Treinamento comportamental: Uma alternativa de atendimento à população não clínica. $R e$ vista de Psicologia, 3(1), 67-81. 
Del Prette, A.; Del Prette, Z. A. P. \& Barreto, M. C. M. (1999). Habilidades sociales en la formación profesional del psicólogo: Análisis de un program de intervención. Psicologia Conductual, 7(1), 27-47.

Del Prette, Z. A. P. \& Del Prette, A. (1996). Habilidades sociais: Uma área em desenvolvimento. Psicologia: Reflexão e Crítica, 9(2), 287-389.

Del Prette, Z. A. P. \& Del Prette, A. (1997). Habilidades sociais e construção de conhecimento em contexto escolar. Em D. R. Zamignati (Org.), Sobre Comportamento e Cognição (p. 234-250). Santo André: ARBytes Editora, $3^{\circ}$ Vol.

Del Prette, Z. A. P. \& Del Prette, A. (1999). Psicologia das Habilidades Sociais: Terapia e educação. Petrópolis: Vozes.

Del Prette, Z. A. P. \& Del Prette, A. (2000). Treinamento em habilidades sociais: Panorama geral da área. Em V. G. Haase; R. R. Neves; C. Kapler; M. L. M. Teodoro \& G. M. O. Wood (Orgs.), Psicologia do desenvolvimento: Contribuições interdisciplinares (p. 249-264). Belo Horizonte: Editora Health.

Del Prette, A. \& Del Prette, Z. A. P. (2001a). Habilidades sociais: Biologia evolucionária e cultura. Em H. J. Guilhardi; M. B. B. P. Madi; P. P. Queiroz \& M. C. Scoz (Orgs.), Sobre comportamento e cognição (p. 65-75). Santo André: ESETec.

Del Prette, Z. A. P. \& Del Prette, A. (2001b). Psicologia das relações interpessoais. Vivências para o trabalho em grupo. Petrópolis: Vozes.

Del Prette, Z. A. P.; Del Prette, A.; Garcia, F. A.; Silva, A. T. B. \& Puntel, L. P. (1998). Habilidades sociais do professor em sala de aula: Um estudo de caso. Psicologia: Reflexão e Crítica, 11(3), 591-603.

Del Prette, Z. A. P.; Del Prette, A.; Torres, A. C. \& Pontes, A. C. (1998). Efeitos de um programa de intervenção sobre aspectos topográficos das habilidades sociais de professores. Psicologia Escolar e Educacional, 2(1), $11-22$.

Delitti \& Meyer (1998). O uso dos encobertos na prática da terapia comportamental. Em Psicoterapia comportamental e cognitiva dos transtornos psiquiátricos ( $\mathrm{p}$. 269-274). Campinas: Editorial Psy II.

Falcone, E. M. de O. (1998). Grupos. Em B. Rangé (Org.), Psicoterapia comportamental e cognitiva: Pesquisa, prática, aplicações e problemas (p. 159-169). Campinas: Editorial Psy II.

Hidalgo, C. G. C. \& Abarca, N. M. (1992). Comunicación interpersonal: Programa de entrenamiento en habilidades sociales. Santiago: Ediciones Universidad Católica.
MacKay, D. (1988). Dificuldades sociais e interpessoais. Em H. W. Lettner \& B. P. Rangé (Orgs.), Manual de psicoterapia comportamental (p. 137-148). São Paulo: Editora Manole.

Manual do Conselho Regional de Psicologia de São Paulo (1999). Conselho Regional de Psicologia - São Paulo.

McFall, R. M. (1982). A review and reformulation of the concept of social skills. Behavioral Assessment, 4, 1-33.

Meyer, S. B. (1997). O conceito de análise funcional. Em M. Delitti (Org.), Sobre comportamento e cognição (p. 31-36). Santo André: Arbytes Editora.

Sidman, M. (1995). Coerção e suas implicações. Campinas: Editorial Psy II.

Silva, A. T. B. (2000). Problemas de comportamento e comportamentos socialmente adequados: Sua relação com as habilidades sociais educativas de pais. Dissertação de Mestrado. Universidade Federal de São Carlos.

Silva, A. T. B.; Del Prette, A. \& Del Prette, Z. A. P. (2000). Relacionamento pais-filhos: Um programa de desenvolvimento interpessoal em grupo. Psicologia Escolar $e$ Educacional, 3(3), 203-215.

Skinner, B. F. (1984). Selection by consequences. The behavioral and brain sciences, 7(4), 477-481.

Skinner, B. F. (1992). Verbal behavior. Cambridge: B. F. Skinner Foundation (originalmente publicado em 1957).

Skinner, B. F. (1993a). Ciência e comportamento humano ( $8^{\mathrm{a}}$ ed.). São Paulo: Martins Fontes (originalmente publicado em 1953).

Skinner, B. F. (1993b). Sobre o behaviorismo (9a ed.). São Paulo: Cutrix (originalmente publicado em 1974).

Skinner, B. F. (1995). Questões recentes na análise comportamental ( $2^{\mathrm{a}}$ ed.). Campinas: Papirus (originalmente publicado em 1989).

Sturmey, P. (1996). Functional analysis in clinical psychology. England: John Wiley \& Sons.

Torós, D. (1997). O que é diagnóstico comportamental. Em Em M. Delitti (Org.), Sobre comportamento e cognição (p. 98-103). Santo André: Arbytes Editora.

Tourinho, E. Z. (1995). O surgimento do Behaviorismo Radical de B. F. Skinner. Em $O$ autoconhecimento na psicologia comportamental de B. F. Skinner (p. 1-23). Belém: Editora UFPa.

Tourinho, E. Z. (1999). Eventos privados em uma ciência do comportamento. Em Sobre comportamento e cognição (p. 174-187). Santo André: Arbytes Editora.

Recebido: 10.11 .2002

Revisado: 22.11.2002

Aceito: 10.12 .2002

\footnotetext{
Notas:

${ }^{1}$ Relações sociais são consideradas por Hinde (1981, Em Del Prette \& Del Prette, 1999) como um fenômeno amplo que inclui a análise da qualidade, conteúdo, forma e freqüência das interações interpessoais, bem como afetam e são afetados por variáveis contextuais.

2 Para saber mais sobre eventos privados, vide, por exemplo, Skinner (1995/1989; 1993a/1953; 1993b/1974); Tourinho (1999), Delitti e Meyer (1998) e Abib (1997).

${ }^{3}$ A definição de Skinner (1992/1957) para comportamento verbal e não-verbal difere desta apresentada. Para este autor o comportamento verbal é um operante cujas conseqüências são mediadas por ouvinte treinado, e o comportamento não-verbal ocorre quando o organismo atua diretamente no ambiente físico, modificando-o e sendo modificado, sem mediação verbal.

${ }^{4}$ Para mais detalhamento, vide Davis (1975).

${ }^{5}$ Para saber mais sobre análise funcional, vide, por exemplo, Skinner (1993/1953), Sturmey (1996), Meyer (1997) e Andery, Micheletto e Sério (2001)

${ }^{6}$ Para conhecer mais sobre os trabalhos de pesquisa desenvolvidos na área, vide revisão de Del Prette e Del Prette (2000).

${ }^{7}$ Del Prette e Del Prette (2001b) descrevem diversas vivências para grupos.
} 


\section{Sobre a autora}

Alessandra Turini Bolsoni-Silva: Doutoranda pelo Programa de Pós-Graduação em Psicologia, da Faculdade de Filosofia, Ciências e Letras (FFCL) da Universidade de São Paulo (USP - Campus Ribeirão Preto). Professora Assistente do Departamento de Psicologia da Faculdade de Ciências da Universidade Estadual Paulista (UNESP - Campus Bauru). Endereço para correspondência: Eng. Luiz Edmundo C. Coube, s/n - CEP 17.033.360 - Bauru, SP - E-mail.: bolsoni@ fc.unesp.br - Fone/Fax: (0xx14) 221.6087 
